\title{
Gestão social como projeto político e prática discursiva
}

\author{
ALAN Ferreira de Freitas \\ Universidade Federal de Viçosa / Departamento de Administração e Contabilidade, Minas Gerais-MG, Brasil \\ ALAIR FERreira de Freitas
}

Universidade Federal de Viçosa / Departamento de EConomia RuRAL, Minas Gerais-MG, Brasil

MARCo AUrélio MARQUes Ferreira

Universidade Federal de Viçosa / Departamento de Administração e Contabilidade, Minas Gerais-MG, Brasil

\section{Resumo}

O objetivo deste trabalho é discutir em que medida a gestão social se configura como projeto político em direção a uma sociedade mais democrática, a um Estado menos classista, partindo do desvelo das bases epistemológicas da administração pública gerencial e da dicotomia entre política e administração. Assim, queremos revelar seu caráter emancipador, ao transformar o poder comunicativo, que emerge das esferas públicas livres, em poder administrativo, influenciando as decisões do Estado e evitando a colonização do mundo da vida pelos ideais normativos e instrumentais do Estado e do mercado.

Palavras-chave: Gestão social. Administração pública gerencial. Esfera pública.

\section{Social management as a political project and a discursive practice}

\section{Abstract}

This paper aims to discuss to what extent social management is configured as a political project towards a more democratic society, a less classist State, starting from the analysis of the epistemological foundations of managerial public administration and the dichotomy between politics and administration. Thus, we intend to reveal its emancipatory nature, by transforming the communicative power, which emerges from the free public spheres, in administrative power, influencing the State's decisions and preventing a colonization of the life world by normative and instrumental ideals of the State and the market.

Keywords: Social management. Managerial public administration. Public sphere.

\section{Gestión social como proyecto político y práctica discursiva}

\section{Resumen}

El objetivo de este trabajo es discutir en qué medida la gestión social se configura como un proyecto político hacia una sociedad más democrática, un Estado menos clasista, en base a la solicitud de las bases epistemológicas de la administración pública gerencial y la dicotomía entre política y administración. Así, queremos revelar su carácter emancipador, al transformar el poder comunicativo, que emerge de las esferas públicas libres, en poder administrativo, influyendo en las decisiones del Estado y evitando la colonización del mundo de la vida por los ideales normativos e instrumentales del Estado y del mercado.

Palabras clave: Gestión social. Administración pública gerencial. Esfera pública. 


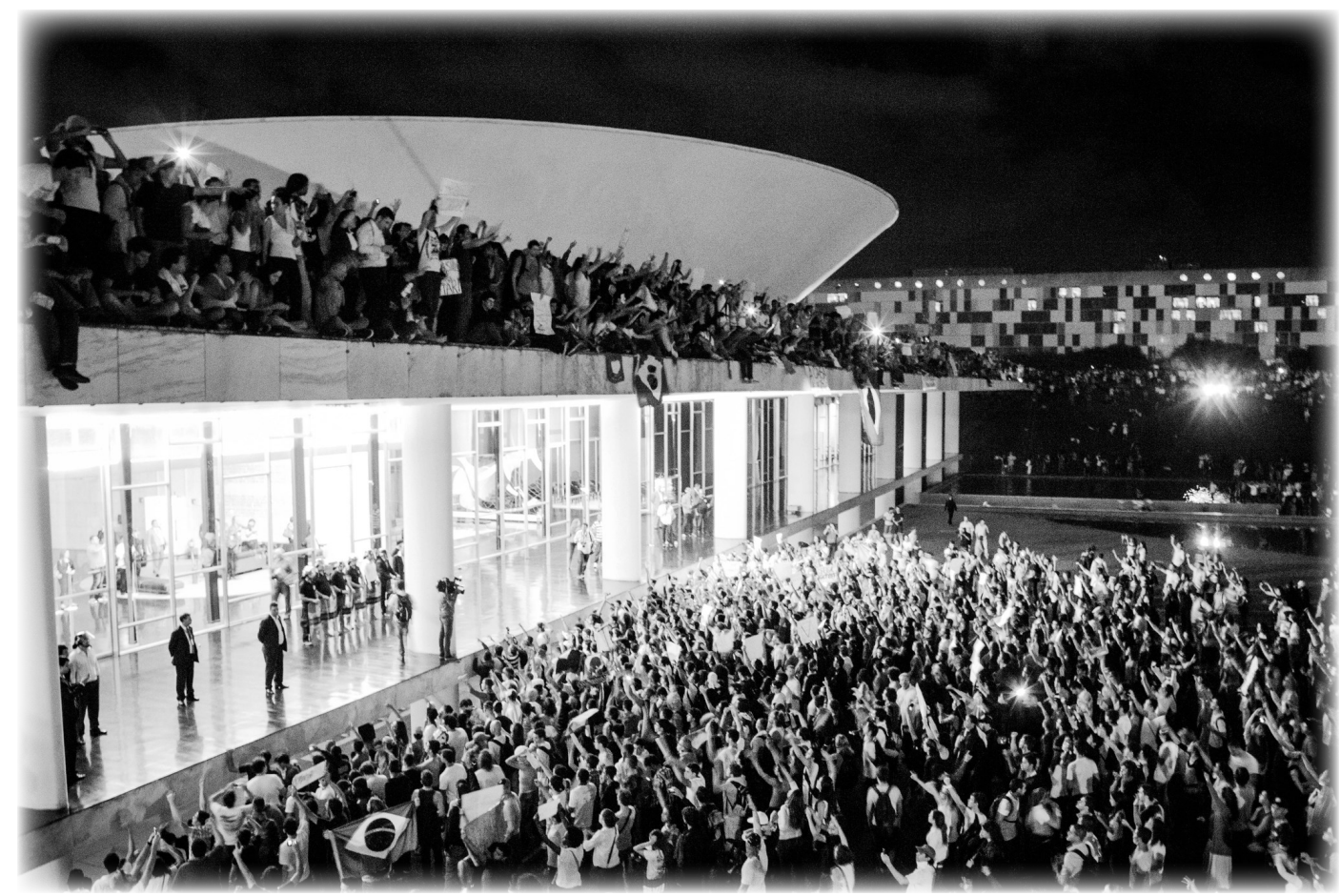

\section{INTRODUÇÃO}

No Brasil, ainda há grande imprecisão conceitual em relação à noção de Gestão Social. Não obstante, tem se tornado cada vez mais comum a sua aplicação como fundamento para muitas práticas participativas e políticas públicas cunhadas pelo Estado. Seu apelo ao "social" e à "participação" tem sido fundamental, ao menos na retórica, para sua integração como norteador de formas de interação entre Estado e Sociedade Civil e para legitimar certas práticas e demandas da sociedade.

Para muitos administradores públicos, a participação social deve ser integrada, prática e discursivamente, às políticas (policy), para haver convergência com a democracia que funda nosso sistema de governo, ressignificando a política (politic). Porém, a participação, ou a própria gestão social podem ser incorporadas a políticas públicas de forma instrumental, sem nenhum caráter eminentemente político. Isso instiga a reflexão sobre o uso do termo Gestão Social como prática. Contudo, aponta para a necessidade de entendê-la a partir de um sentido ideológico, assumindo-a também como um projeto político, que ressalta um objetivo de transformar a realidade política.

O objetivo deste ensaio é discutir em que medida a Gestão social se configura como um "novo" projeto político ${ }^{1}$ em direção a uma sociedade mais democrática e a um Estado menos classista, partindo das bases epistemológicas da administração pública gerencial. Nessa direção, campo científico da gestão social e sua inserção como elemento de políticas públicas propicia revelar e emergir, ao debate da academia e do Estado, experiências sociais até então sem qualquer reconhecimento e validade. Com isso, a gestão social se insere no contexto da sociologia das ausências e das emergências, desenvolvida por Santos (2002).

\footnotetext{
* Fonte da imagem: Disponível em <http://apolinariopassos.com.br/blog/como-manter-o-povo-unido-qual-e-o-foco/>. Acesso em 01 mar. 2016.
}

${ }^{1}$ O termo projeto político, que será amplamente utilizado no texto, está definido de acordo com Dagnino (2004, p. 164), inspirada em Gramsci, que considera o projeto político para designar um conjunto de "crenças, interesses, concepções de mundo, representações do que deve ser a vida em sociedade, que orientam a ação política dos diferentes sujeitos". 
Ao perseguir o objetivo deste trabalho, pretendemos esclarecer que num contexto histórico de redemocratização do Brasil, onde a sociedade civil se fez protagonista na reforma do Estado e do surgimento de novas formas de gestão pública, podemos identificar modelos de gestão distintos. De forma central, de um lado existem modelos focados numa perspectiva gerencialista, cunhada em resultados e na busca da eficiência da máquina pública; do outro, uma gestão mais "social", focada na participação da sociedade civil e na permeabilidade do Estado.

Um pressuposto central de que lançamos mão neste texto refere-se às racionalidades que guiam as diferentes formas de gestão, tanto no âmbito público quanto no privado. No modelo gerencialista da gestão pública, procuramos evidenciar uma racionalidade instrumental existente neste campo epistemológico, bem como em sua reprodução enquanto modelo de gestão. Porém, tornou-se necessário refletir sobre a ideia de que, em determinados discursos e contextos, pode não haver uma dicotomia entre os dois modelos de gestão (ou projetos políticos divergentes), mas uma "confluência perversa", para utilizar o termo cunhado por Dagnino (2004). Nos desígnios da autora, a perversidade estaria colocada no fato de que, apesar de apontarem para direções opostas e até antagônicas, ambos requerem uma sociedade civil ativa e propositiva.

A confluência levantada por Dagnino (2004) considera que ambos os projetos políticos que conduzem os modelos de gestão pública são portadores de um discurso que prega a ampliação da democracia no país. É nesta direção que procuramos descortinar as bases epistemológicas do gerencialismo e trazer à baila a diferença entre projetos políticos distintos que assumem o caráter de disputa de sentido para significar importantes noções, como "participação" e "cidadania". Neste sentido, deve estar claro que democratizar uma organização pública e viabilizar a participação popular são tarefas distintas, caso contrário, estaríamos correndo o risco de deslocar o sentido dos termos e cair num equívoco semântico e conceitual.

Para que o adjetivo "social" que qualifica a "gestão" no âmbito da administração pública e dos processos democráticos não seja apropriado indiscriminadamente e despolitizado, propomos uma aproximação com a noção de esfera pública política habermasiana, como instituidora do projeto político cunhado pela gestão social. A teoria habermasiana fundamenta um paradigma linguístico, sob o qual podemos entender a gestão social enquanto prática discursiva mediante o uso de um poder comunicativo.

Apropriamos desta abordagem como opção teórico-metodológica para um modelo de análise da racionalidade das ações no âmbito da Administração Pública, ou seja, das ações do Estado e de sua necessária relação com a sociedade civil. Para isso, ao denotar uma racionalidade comunicativa, a teoria habermasiana sedimenta uma forma de pensar a instrumentalidade da administração pública gerencial e uma nova interpretação da dicotomia Política versus Administração. De forma complementar, a noção de racionalidade em Guerreiro Ramos (1989) também foi mobilizada para trazer à tona sua ênfase aos processos de gestão e organização.

Sobre este aporte analítico, o foco do trabalho deixa de ser as prescrições sobre como os agentes podem fazer para fortalecer uma gestão social, em função de discutir como o uso livre e racional da linguagem e do discurso, fundamentada numa esfera pública política, é o alicerce da capacidade de influência nas decisões do Estado e na sua mudança de racionalidade. Embora o debate prescritivo e normativo possa estar presente em algumas partes do texto, ele só entra em cena para delimitar criticamente os conceitos operados nas discussões teóricas.

Temos claridade de que, ao tentar percorrer este inóspito caminho teórico da gestão social, corremos o risco de sermos superficiais em nossas análises, pois não há um conceito consolidado e bem fundamentado. Porém, a partir da literatura recente e dos avanços teóricos no campo científico da gestão social, optamos por correr esse risco em direção a mais um avanço teórico. Primeiro trazendo, a noção de gestão social como projeto político em direção a uma gestão pública mais participativa e democrática; e depois estabelecendo uma relação entre a gestão social e as práticas discursivas cunhadas por Habermas na sua teoria da ação comunicativa e na ideia de esfera pública política. O apontamento do papel da gestão social na visibilidade e credibilidade de experiências desperdiçadas, ou seja, sua relação com a sociologia das ausências e das emergências também merece lugar de destaque.

A noção de gestão social aqui delimitada como projeto político e prática discursiva recai neste ensaio como um tipo ideal weberiano ${ }^{2}$, tomado como referência à ação e orientador do processo político-estrutural de racionalização e democratização

\footnotetext{
2 Para Weber (2001, p. 139), "a construção de tipos ideais abstratos não interessa como fim, mas única e exclusivamente como meio de conhecimento". Ou seja, a construção de tipos ideais não é o propósito último da elaboração teórica, mas compõe o instrumental que será suporte para o alcance de seus objetivos na interpretação dos fenômenos sociais.
} 
da esfera pública. Tais reflexões são ainda passos iniciais de uma empreitada teórica, mas buscam sublinhar novas rotas para ampliar os horizontes do chamado Campo Científico da Gestão Social. Este debate justifica necessariamente a ambição do texto em descortinar a dicotomia entre política e administração. Para isso, o foco precisa recair sobre uma dimensão específica da administração pública: a relação entre Estado e Sociedade Civil.

Para desenvolver essa proposta, o texto foi organizado em quatro seções além desta introdução. Na primeira, procuramos discutir as bases do projeto político da administração pública gerencial, enumerando características distintivas e a ideologia gerencialista. Na segunda seção, debatemos a emergência da noção de gestão social e suas contribuições em direção a uma proposta democratizante e participativa da administração pública. Na terceira seção, trazemos elementos teóricos da noção de esfera pública, ação comunicativa e mundo da vida como dimensões conceituais básicas da interpretação da gestão social como projeto político para a administração pública. Por fim, apresentamos algumas conclusões.

\section{BASES DO GERENCIALISMO NA ADMINISTRAÇÃo PÚBLICA}

Giddens (2001), mencionando as contribuições da teoria marxista, afirma que a formação da vida social moderna esteve, a todo custo, influenciada pela produção industrial, o que ajuda a compreender a expansão capitalista no desenvolvimento dos Estados modernos e das instituições. Por sua vez, arraigadas num certo tipo de racionalidade, as instituições modernas usam seu conhecimento sobre as condições de reprodução do sistema de modo reflexivo para influenciar, dar forma ou modificar o próprio sistema (GIDDENS, 2001).

Essa racionalidade, chamada de instrumental, portanto, está enraizada na sociedade capitalista e é a base para o modelo gerencialista de gestão, convocado para lograr objetivos no setor público. Objetivos esses voltados para a eficiência e eficácia nas contas e finanças públicas, melhoria de performance e efetividade das organizações públicas, com base nas raízes exitosas da iniciativa privada (SOUSA e PAIVA JR. 2010). A busca da legitimidade social e o discurso da participação também fizeram parte (e ainda fazem) deste projeto para garantir a reprodução do sistema. Fato confirmado pela lógica instrumental gerencialista que coloca o cidadão como cliente do Estado no processo de relação entre Administração Pública e Cidadão. Ao mesmo tempo, exige desse a participação como forma de legitimar na democracia republicana o conceito de governo para o povo e pelo povo.

Para Paes de Paula (2005), o debate sobre o gerencialismo na administração pública teve início com um movimento de reforma do Estado iniciado na Europa e nos Estados Unidos, cuja principal inspiração era o governo de Margareth Thatcher. No Brasil, a administração pública gerencial se institui com o governo de Fernando Henrique Cardoso e está ligada ao crescente discurso da crise da governabilidade e da descredibilidade do Estado. Embora o Decreto-Lei 200/1967³ do Governo de Marechal Castello Branco, mesmo diante de certo anacronismo, seja considerado primeira expressão dos ideais gerenciais para o país, ao instituir normas de organização da Administração Federal e estabelecer diretrizes para as reformas administrativas que colocaram o cidadão como foco da ação pública e beneficiário da ação do Estado.

O movimento gerencialista foi identificado por autores como Fadul e Souza (2006), como uma estratégia de enfrentamento à ineficiência da administração pública burocrática, de baixa qualidade, com salários incompatíveis com a realidade do país. Em um contexto mais amplo, os referidos autores esclarecem que as denominações nova administração pública ou administração pública gerencial referem-se às bases da reforma administrativa do setor público.

Cada vez mais, o pensamento gerencial influenciou os modelos de gestão pública em busca de melhores resultados e de legitimidade. Neste movimento, insere-se na administração pública a noção de empreendedorismo e de eficiência como componentes da nova forma de organização da gestão e dos instrumentos que permitiriam maior controle sobre os resultados. Tal modelo passou a estabelecer uma forte interface com modelos gerenciais do setor privado, incorporando instrumentos de gestão e novas racionalidades.

\footnotetext{
${ }^{3}$ Decreto-Lei 200/1967 se refere a organização da Administração Pública Federal, considerado a segunda reforma Administrativa que definiu a existência de entes descentralizados na administração pública.
} 
Diversos autores, como Saravia (2010) e Paes de Paula (2005), apontam que o modelo gerencial de administração pública se concretizou mediante a reestruturação produtiva do capitalismo e a consolidação das grandes corporações influenciadas pelo modelo fordista. Para os autores, o gerencialismo passou a representar muito mais os interesses de diferentes empresas e governantes do que propriamente o interesse geral da sociedade civil.

Na implantação do modelo gerencial para a administração pública brasileira, desencadeado pelo plano diretor de reforma do Estado comandado por Bresser-Pereira no governo Fernando Henrique Cardoso, foram definidas ações exclusivas e não exclusivas do Estado. As atividades não exclusivas eram separadas em serviços de caráter competitivo e as atividades auxiliares ou de apoio. Nos serviços competitivos, estão os serviços sociais em geral e os científicos que seriam prestados pela iniciativa privada e pelas organizações sociais do setor público não estatal. Os serviços auxiliares, como limpeza, transporte e manutenção, seriam em certa medida terceirizados e para isso submetidos à licitação pública (PAES DE PAULA, 2005). Esse processo provocou o afastamento do Estado de serviços públicos essenciais ao mesmo tempo em que provocou a abertura "bem intencionada" para uma maior atuação de organizações não governamentais frente às questões sociais.

Neste processo de reforma do Estado no Brasil, a participação social, garantida como dever do Estado pela constituição de 1988, é claramente excluída dos poderes de decisão, que ficou reservado ao chamado "núcleo estratégico" do Estado (BRESSER PEREIRA, 1996). Com a terceirização e a "parceria" do Estado com organizações sociais, nota-se um movimento do Estado no sentido de se isentar progressivamente de seu papel garantidor de direitos.

Esse processo representou o encolhimento da máquina pública, desestatização de serviços públicos e sua transferência para a sociedade civil, ou seja, o Estado se adequava a um modelo neoliberal que, segundo Dagnino (2004), foi produzido pelo Consenso de Washington. Reside aí um dos contextos da dimensão perversa já mencionada, pois a tão propalada participação social e os espaços institucionais criados para sua materialização não descortinam as intenções que movem a ação do Estado.

Neste enfoque gerencial, a dicotomia entre política e administração, presente na administração pública, direciona seu peso para a administração, num sentido instrumental, gerando certa despolitização da gestão, clássico dos princípios administrativos da área privada. No caso da evidência dessa dicotomia entre política e Administração na administração pública, a administração é um efeito da política, e os problemas administrativos decorrem da forma como a política se configura. Para que essa desintegração não ocorra, torna-se necessária uma politização da Administração e a autonomização da política, com efeito, esse tem sido o trabalho do campo científico da gestão social.

Desta forma, a Gestão Social procura um sistema de administração (e burocrático) que não seja puramente instrumental, mas integrada e permeada pela racionalidade substantiva, como afirmado por Guerreiro Ramos (1989). A questão, como aqui apresentada, é estabelecer formas de conexão entre política e Administração que atendam às necessidades do discurso prático e da inserção social, ao mesmo tempo em que abarca as regulamentações políticas, garantindo a autonomia relativa necessária ao processo de Administração do bem público.

O desafio é que os conteúdos importados do setor privado contrapõem o conteúdo eminentemente político da participação social e da relação e tensão entre Estado e Sociedade Civil, tornando-a por vezes mera formalidade para implementação de políticas públicas. A participação nas decisões sobre os rumos do Estado e as políticas públicas se restringia ao próprio Estado; e a sociedade civil, apesar de também ocupar certos espaços participativos, detinha pouca ou nenhuma capacidade de influenciar decisões políticas. Fato esse que colocava em discussão o próprio conceito de democracia, vez que o termo democracia carrega a concepção de uma forma de organização social e política baseada na capacidade de governo para o povo.

Para Paes de Paula (2005), é central o entendimento de que essa nova administração pública também focou primordialmente a dimensão cultural da organização pública e a dimensão de gestão. No âmbito cultural, residiria a prioridade de transformar a cultura burocrática numa cultura de gestão. No que se refere à gestão, era necessário que os administradores públicos colocassem em prática pressupostos e ferramentas de gestão utilizadas em organizações privadas.

No projeto político gerencialista, encobertos pelo discurso do interesse público, os interesses privados tendem a dominar a esfera pública, por um lado, e a "colonizar" 4 a esfera íntima por meio do consumo, por outro. Os mecanismos de participação, ao contrário de intensificar a interação, afastam os cidadãos da possibilidade de um debate público capaz de engendrar

\footnotetext{
${ }^{4} \mathrm{O}$ termo "colonização" é apresentado na teoria habermasiana para designar a penetração da lógica instrumental nas dinâmicas de vida dos sujeitos. Este termo será mais bem trabalhado ao longo do texto.
} 
fluxos comunicativos hábeis a mudar o rumo das ações estatais. Essa racionalidade instrumental sedimenta o modelo gerencialista e orienta a legitimação de suas práticas utilitaristas como práticas públicas. Tal razão instrumental, numa perspectiva habermasiana, é a razão que coordena as ações dirigidas a fins, os quais passam a não ser mais questionáveis (FREITAG, 1993).

Entretanto, é preciso reconhecer que a missão fundamental do governo é promover o bem comum e zelar pela realização dos serviços públicos, e o da empresa é auferir lucro econômico por meio da elaboração de produtos ou prestação de serviços. Isso nos indica que a racionalidade e a essência da atividade estatal diferem gestão pública de gestão privada, política, de administração. Daí que o interesse mobilizador da empresa privada seja a lucratividade e o das organizações públicas seja a efetividade (SARAVIA, 2010). Para além de uma razão instrumental, consonante com o modelo privado, no setor público, com tais propósitos, deveria sobressair um tipo de racionalidade baseada no diálogo e no consenso, uma razão comunicativa. A diferença entre o modelo de administração do setor privado e do setor público, entre a racionalidade instrumental e a racionalidade comunicativa, é nítida e elucida novamente a dicotomia entre Política e Administração. Para o setor público, e frente a uma razão comunicativa, não pode haver ausência da dimensão política.

O que está em jogo na contraposição entre essas diferentes racionalidades é também, e essencialmente, uma diferença de projetos políticos. No âmago desta questão, está a dimensão ontológica da noção de "público", que pressupõe o "social” e a reinvenção dos processos políticos e emancipatórios. Para OFFE (1995), a nova problemática que tem ocupado o centro do palco desde meados da década de 1960 é caracterizada pelo sentimento crescente da falha do tipo de racionalidade instrumental e pela necessidade cada vez mais sentida de "racionalizar" o organismo político em termo de um novo projeto.

Nessa direção, Habermas (1989) argumenta acerca da necessidade de transformação da atividade administrativa do Estado na expressão de uma atividade legítima da sua comunidade: em uma legitimidade democrática para o exercício do poder administrativo. O exercício do poder administrativo, para Habermas (1989), não pode mais estar baseado em um mero poder formal instrumentalizado, definido segundo regras jurídicas igualmente formais de competência administrativa. Neste caso, retomando a dissonância entre política e administração, a mencionada legitimidade pressupõe um valor político para repensar a razão instrumental, um valor político genuinamente democrático que Habermas vai denominar de razão comunicativa. Essa é a base da ação comunicativa voltada para o entendimento. A ação comunicativa só pode surgir onde há uma livre formação da opinião pública e da vontade geral, que demanda, do Estado e da Administração Pública, novos contornos gerenciais e novas referências de ação.

Habermas (1997) demonstra a possibilidade de conectar o poder administrativo ao poder comunicativo, de modo a torná-lo legítimo. Onde os fluxos comunicativos que se engendram a partir dos diálogos na esfera pública possuem potencial de influenciar o Estado. Para o autor, não são as leis ou os resultados que garantem a legitimidade da ação da administração pública, mas sim o processo democrático do qual ele deriva.

\section{GESTÃo SOCIAL: UM PROJETO POLÍTICO PARA A ADMINISTRAÇÃO PÚBLICA}

A Gestão Social é interpretada nesse texto como projeto político em direção a um Estado efetivamente democrático e permeável. Projeto político no sentido de Dagnino (2004), que, influenciada por Gramsci, o vincula a um ideal de transformação, como uma ideologia que movimenta as ações dos sujeitos. É neste sentido que procuramos ir além das definições prescritivas e despolitizadas, que podem, sobretudo, contribuir com contradições semânticas e acentuar a confluência perversa. Desta forma, ao defendermos gestão social como projeto político, a intenção é politizar a gestão social e colocá-la como prática dialógica capaz de produzir uma crítica à racionalização da sociedade, emancipando-a das armadilhas e da ação colonizadora da razão instrumental.

Cançado, Tenório e Pereira (2011, p. 700) tentam avançar na definição de um conceito de gestão social ao definirem-na como "a tomada de decisão coletiva, sem coerção, baseada na inteligibilidade da linguagem, na dialogicidade e no entendimento esclarecido como processo, na transparência como pressuposto e na emancipação enquanto fim último". Essa definição se aproxima do nosso direcionamento teórico, ao propor um processo discursivo que objetiva a emancipação, mas parece-nos demasiado amplo e genérico, sem considerar as particularidades da gestão em diferentes dimensões, como nas relações entre Estado e Sociedade Civil, e o contexto procedimental necessário à sua aplicação. 
A gestão social ganha contornos mais nítidos nas fissuras do gerencialismo da administração pública. É na sua crise de legitimidade que a administração pública gerencial abre espaço para novas formas de interação entre Estado e Sociedade Civil, de onde se edificam pretensões procedimentais para a modificação do sistema.

Frente a um movimento democrático de oposição a um Estado classista e à administração pública gerencial, ergue-se a defesa de uma esfera pública não burguesa e não estatal, onde há a possibilidade da instituição de espaços públicos de negociação e deliberação. Esta esfera pública política demandava novos formatos e arranjos institucionais para a participação dos cidadãos nas decisões públicas.

Este movimento, no Brasil, foi (e ainda é) permeado por iniciativas localizadas de experiências alternativas de gestão pública focadas principalmente na dimensão da relação entre Estado e Sociedade civil. A construção de canais de participação da sociedade civil na discussão de assuntos públicos culminou no importante surgimento e deflagração dos conselhos gestores, dos fóruns temáticos, dos orçamentos participativos e de muitas outras experiências participativas.

Tais experiências tinham, sobretudo, a intencionalidade de serem mecanismos de influência nas decisões do Estado sobre os rumos dos serviços públicos e os temas das políticas públicas. As reivindicações e a reinvenção da democracia e da gestão pública a partir destes espaços de "co-gestão" demandavam um projeto político mais abrangente, que contemplasse: "a) um novo modelo de desenvolvimento para o Brasil, capaz de superar a crise do nacional desenvolvimentismo; b) uma proposta de reorganização para o aparelho de Estado; e, c) uma visão de gestão pública alternativa ao gerencialismo" (PAES DE PAULA, 2005, p. 40).

O desafio está em concretizar esse projeto político no mundo da vida, no lócus das relações e das práticas sociais. E, assim, ampliar a capacidade de ação dentro da esfera pública, que exige uma maior flexibilidade da administração pública a partir de seu direcionamento aos processos discursivos engendrados na sociedade civil. Com esta proposta, o antagonismo que marcava profundamente a relação entre o Estado e a sociedade civil cede lugar à possibilidade da sua ação conjunta para o aprofundamento democrático (DAGNINO, 2004).

Na literatura que trata do tema Gestão Social, a discussão parece ganhar saliência a partir dos processos de democratização e descentralização político-administrativa. Em geral, este processo implica a inclusão de temáticas até então ignoradas pelo sistema político, a redefinição de identidades e vínculos e o aumento da participação em nível local, possibilitando uma gestão pública com a participação da sociedade civil (SANTOS e AVRITZER, 2002).

Entre os teóricos brasileiros contemporâneos de maior expressão nas pesquisas sobre o tema da gestão social (TENÓRIO, 1998; 2008; FRANÇA FILHO, 2003; 2008; JUNQUEIRA, VINHAS, PERRET et al., 2009; etc.), o conceito tem sido usado eminentemente para identificar as mais variadas práticas sociais de diferentes atores. Esta literatura sinaliza para a discussão do conceito de cidadania deliberativa, focando na constituição de espaços de participação onde a sociedade assuma uma postura ativa, na formulação, implementação e avaliação das políticas públicas.

De maneira geral, enquanto prática social, a gestão social pode ser entendida como um processo no qual o Estado, sem perder a centralidade, deixa de ter o monopólio do poder para - juntamente com a Sociedade Civil - planejar, traçar diretrizes e tomar decisões capazes de potencializar as riquezas, em sentido amplo, do local (CARRION e CALOU, 2008).

A prática da gestão social, porém, pressupõe a organização da sociedade civil e sua presença efetiva no processo de construção e tomada de decisões no interior do Estado. A materialização desse processo parece ser possível por meio do fortalecimento de esferas públicas comunicativas e das possibilidades de diálogos. Faz-se necessário buscar maneiras de conciliar necessidades particulares e interesses mais gerais da sociedade. Pois, para Habermas (1997), o indivíduo se constitui na ação discursiva e, nessa mesma prática, produz, molda e modifica seu contexto social e político.

Neste sentido, a prática discursiva da gestão social busca a formação de consensos, extraindo da participação social a legitimidade, buscando o controle sobre os serviços públicos. As ações no âmbito da gestão social buscam a construção do entendimento mútuo e se instaura no mundo das intersubjetividades ${ }^{5}$. Isto é, há um processo de interação entre as subjetividades, onde as posições individuais são relativizadas frente à construção do entendimento coletivo.

${ }^{5}$ Esta ideia deriva da ética discursiva de Habermas. 
O aspecto político tem, portanto, uma relevância central nesta noção que permite exatamente não reduzi-la à esfera governamental e à administração. A gestão social supõe assim, antes de tudo, uma ação política dos sujeitos no sentido de agirem num espaço público de caráter deliberativo, posicionando-se, mediando conflitos e estabelecendo consensos. Estas instituições deliberativas fornecem, segundo Evans (2003, p. 23), "bases mais sólidas para avaliar as prioridades de desenvolvimento, (...) dando aos cidadãos a oportunidades de exercer a capacidade humana fundamental de fazer escolhas".

Por esta via, argumentamos que a prática da gestão social só pode ser desencadeada por uma esfera pública democrática, que ganha contiguidades a partir da constituição de espaços institucionais de participação e diálogo, representando uma articulação intrínseca entre Estado e sociedade civil. A gestão social pressupõe, então, a ação (comunicativa) neste espaço público e a ampliação das possibilidades de influir e avaliar as prioridades de desenvolvimento, pois os sujeitos interagem no espaço público e podem interferir na realidade social.

Porém, devemos alertar, sem receio de receber críticas, que o termo gestão social claramente pode revelar ambiguidades e pode incorrer no equívoco semântico que reforce a perversidade de uma confluência. Assim, a confluência perversa, que se insere numa crise discursiva (DAGNINO, 2004), pode ocorrer a partir da apropriação do termo "gestão social" por um projeto político distinto e de oposição, vinculado à cultura do gerencialismo, tornando-se um mero dispositivo discursivo, dissonante da prática emancipatória.

No entanto, não vemos alternativas de definir nomenclaturas e experiências que não possam correr este risco. Mas as bases epistemológicas da gestão social e suas derivações práticas é que fortalecem e a reafirmam nesse campo de disputas. Para lograr caminhos mais virtuosos e fugir das falácias ou dos equívocos semânticos, o campo da gestão social na administração pública precisa aprofundar suas bases teóricas e apropriar-se da esfera pública como categoria instituidora de seu projeto político. Para contornar melhor as arestas deste campo científico, procuramos definir, de acordo com a literatura, características que são próprias do uso semântico do termo Gestão Social, além de revelar o seu potencial de desvelar experiências sociais perdidas e invisíveis às logicas da academia e do Estado.

\section{Características definidoras e o potencial revelador}

Podemos e devemos compreender a emergência da Gestão Social diante daquilo que Santos (2002) chama de desperdício de experiência, onde a riqueza social das experiências alternativas não pode ser desperdiçada, ou seja, há muita experiência social invisível aos olhos dos pesquisadores das áreas de ciências sociais. Trazemos essa noção para afirmar que o campo da gestão social tem se tornado campo de visibilidade de experiências de organizações alternativas, de formas de gestão contrárias ao sistema tradicional. Por isso mesmo, a razão comunicativa e a substantiva se tornam relevantes às análises empregadas pelo campo.

Frente ao desperdício de experiências é que as contribuições de Habermas e Guerreiro Ramos, que serão apontadas no decorrer do texto, tornam-se cada vez mais importantes para compreender as alternativas à colonização do mundo da vida, à penetração da lógica utilitarista na condução da ação humana e no sentido dado às organizações. A Gestão Social, nesse caminho, como projeto político, ou contrário àquilo que se tornou o tradicional, constrói novos rumos, sobretudo, de interpretação das experiências alternativas de gestão (pública e privada) e de organização. Serve assim, para combater o desperdício da experiência e tornar visíveis processos gerenciais e organizacionais, dando-lhes credibilidade. Segundo Santos (2002), para combater esse desperdício da experiência social, não basta simplesmente propor novas configurações das ciências sociais, é preciso pensar numa nova racionalidade.

A ideia de confluência perversa, posta por Dagnino (2004), reside exatamente na forma e no fim do uso conceitual de um termo, balizado pela razão que está por trás desse uso. Gestão social pode ser usado para caracterizar uma forma de administração em que o "patrão" confere alguma forma de participação aos "empregados". Ainda assim, mantém-se a lógica produtivista e a subordinação do trabalho. Porém, Gestão Social é constantemente utilizada para revelar formas de gestão coletiva, onde os meios de produção também são coletivos, como cooperativas e associações, além de outras experiências de participação social que contrariam a lógica da eficiência e da burocracia. Neste segundo cenário, as experiências sociais, no campo da Gestão Social, ganham relevância e são passíveis de análise. 
Para Santos (2002, p. 249), tornar as experiências presentes e visíveis significa "serem consideradas alternativas às experiências hegemônicas, a sua credibilidade poder ser discutida e argumentada e as suas relações com as experiências hegemônicas serem objeto de disputa política". Desta forma, essa sociologia das ausências, proposta por Santos (2002), permite libertar as experiências alternativas da condição de resíduo, qualificando as práticas sociais, e de gestão social, firmadas por uma racionalidade que elimina a instrumentalidade e o utilitarismo.

Nesta direção, a banalização do conceito de Gestão Social em tempos de modismos conceituais torna oportuna as discussões e esforços de delimitação do campo para além de mero discurso político. Nesse esforço, Cançado, Pereira e Tenório (2013) fizeram um levantamento das características básicas da gestão social baseado em trabalhos de autores que se tornam referência na área. Segundo os autores supracitados, a "tomada de decisão coletiva" é um elemento basilar que perpassa por todas as análises realizadas no campo da Gestão Social.

Sem grande esforço interpretativo, a tomada de decisão coletiva imprime à discussão outros elementos, que são caros aos estudiosos da área. O próprio sentido de "coletivo" deve ser mais bem esclarecido para delimitar o viés de análise. Podemos falar de deliberações na esfera pública, ou de decisões coletivas numa organização cooperativa. A nosso ver, é mister entender que toda decisão coletiva perpassa por três pilares, dos quais dois foram citados por Cançado, Pereira e Tenório (2013), sendo (i) Diálogo e (ii) Consenso, chamados pelos autores de "entendimento". Porém há outro, sobre o qual se assentam estes dois últimos, a (iii) Autonomia.

Primeiro, é preciso entender que a prática argumentativa que leva as decisões coletivas se fundamenta em espaços discursivos institucionalizados e que estes são constantemente influenciados pelas lógicas das intervenções midiáticas. Nesse caso, instrumentalizam-se e privatizam o político e o público. O problema que incorre dessa questão é a substituição das práticas políticas argumentativas por discursos vazios, despolitizados e de base instrumental e utilitário. Pode haver a cooptação da decisão até então considerada "coletiva". A dialogicidade autêntica baseada na liberdade comunicativa, como apontado por Cançado, Pereira e Tenório (2013), impele a necessidade da transparência como condição necessária ao processo decisório.

Traduzindo à nossa realidade diária, surgem os desafios, sobretudo, teóricos, de compreender, por exemplo, em como colocar em prática uma cultura do diálogo? E onde as relações de poder e dominação estão arraigadas à cultura local, como fica a tomada de decisão coletiva? E onde há interesses partidários e corrupção? Estes questionamentos nos levam a compreender que, mesmo que se firme na retórica a ideia de gestão social ou coletiva, onde se instrumentaliza e torna utilitária a prática do discurso, seu objetivo é convencer e até mesmo impor o seu ponto de vista aos demais. Normalmente, se almeja obter algum tipo de benefício em decorrência das participações nos processos "dialógicos".

Para Marques (2013), os dilemas apresentados acima podem ser pensados por meio de uma ética discursiva, estabelecida por Habermas. Segundo a autora, para Habermas, a ética e também a moral implicam a superação de interesses particulares e a participação em um diálogo sem coerção, onde os participantes devem adotar o "ponto de vista moral" e nunca seus interesses particulares. Desta forma, a busca do "entendimento" ou do "consenso" seria uma consequência da tomada de decisão coletiva.

Neste caso, precisamos compreender que o discurso está ligado diretamente à comunicação, e a moral e a ética ligadas à ação humana. Há, nessa direção, uma unidade entre discurso e ação. Em outras palavras, procuram-se os fundamentos para um bom agir na própria estrutura do processo argumentativo. O que está em jogo neste pensamento Habermasiano não é uma ética para discursos, que diz como devemos nos comunicar, mas conceber o processo comunicativo como uma ação (MARQUES, 2013). Certamente, o mundo da vida, o real, é diferente do ideal discursivo de Habermas, mas suas contribuições ampliam nossas possibilidades de entendimento sobre os fenômenos que nos rodeiam.

Na busca pelo processo de entendimento, definido como consenso, os desafios Habermasiano é entender como é possível, na modernidade, onde as sociedades são cada vez mais complexas, pluralistas e multiculturais, sociedade e pessoas chegarem a um consenso sobre o que é certo e errado? Para Marques (2013), Habermas quer demonstrar que a resposta para esse dilema depende da conexão de demandas de natureza subjetiva, ligadas a diferentes concepções de bem viver, a demandas morais que dizem respeito a como nos relacionamos com outros na busca pela definição de regras e normas vistas como justas para todos. A ética do discurso, enquanto interação comunicativa, permite não só o estabelecimento de consensos, mas a concretização da autonomia política dos sujeitos em diálogo. 
Para Marques (2013), a autonomia no processo de formação do sujeito político em Habermas é essencialmente um processo de construção intersubjetivo e exige competências comunicativas originadas das redes interativas que as pessoas estabelecem umas com as outras. Cançado, Pereira e Tenório (2013) também trazem a intersubjetividade como pressuposto da construção de acordos coletivos e da formação discursiva. Esses autores apontam dois princípios importantes do diálogo: a inteligibilidade e a verdade. Para Marques (2013), esses dois elementos são condições sine qua non, para a construção do discurso moral.

A intelegibilidade e a verdade, juntamente com os outros elementos característicos da gestão social, são pressupostos de sua delimitação conceitual, como afirmado por Cançado, Pereira e Tenório (2013). Diante dos argumentos expostos, a gestão social perpassa pelo uso racional da linguagem, de forma autônoma, inteligível, dialógica e consensual. Assim, discurso e ação se entrelaçam na construção do sujeito político e do processo participativo. O consenso é apenas um resultado temporário do processo dialógico, e isso o caracteriza, pois o processo comunicativo, engendrado na esfera pública, nunca pode ser tomado como acabado, porque, em essência, é intersubjetivo e mutável.

\section{A ESFERA PÚBLICA COMO LÓCUS DE LEGITIMAÇÃO DA GESTÃO SOCIAL.}

A esfera pública, que se configura na teoria habermasiana como lócus da ação comunicativa, de legitimação da participação social, apresenta-se como forma de viabilizar e garantir a consecução do projeto político do que chamamos de gestão social. Caberá necessariamente a luta pela qualidade da prática discursiva e pela qualificação do adjetivo "social", assegurando que os direitos e a vontade geral sejam norteadores dos processos políticos do Estado.

Habermas (1997) desenvolve o conceito de esfera pública comunicativa para acentuar sua ênfase ao que designa de deliberative democracy. Ela está baseada na sociedade civil - que se ancora no "mundo da vida" - a partir de onde se institucionaliza canais de comunicação, que geram um "poder comunicativo" capaz, não de substituir a administração pública gerencial ou o poder do Estado, mas, legitimamente, de influenciá-los.

A prática dos ideais da gestão social está relacionada com uma ação comunicativa. O agir comunicativo, para Habermas (1989), é o processo dialógico voltado ao entendimento mútuo, de negociação, de interpretações comuns, através da racionalidade do discurso. Essa racionalidade (comunicativa neste caso) é a capacidade dos sujeitos em construir um discurso a partir de um procedimento argumentativo.

A ação comunicativa é essencialmente integrativa, e a ação instrumental age sobre essa integração expressando as distintas possibilidades de influência de um ator sobre o outro. Para Magalhães (2003, p. 26), Habermas pretende demonstrar que até mesmo "uma ação estratégica rumo a um fim só é possível pelo estabelecimento anterior de entendimento entre os agentes: o agir comunicativo é, para ele, logicamente, anterior ao agir estratégico". Para o autor, o caráter social do agir só pode ser acessado pelo uso da linguagem e tem sua origem no mundo da vida.

O mundo da vida pode ser entendido como o âmbito da vida social, privada e associativa, em que são produzidos os fluxos comunicativos e realçados os assuntos relevantes que vão sendo discutidos na esfera pública e se tornam públicos. Magalhães (2003), ao interpretar Habermas, reafirma que no mundo da vida se estruturam ações baseadas no uso da linguagem:

Nos termos de Habermas, o mundo da vida é o lugar de geração do entendimento comunicativo, e expressa a criação e a sedimentação de procedimentos simbólicos, atos de fala e expressões da cultura, que pré-estruturam a ação: são os elementos tomados como dados intersubjetivos pelos agentes e sujeitos falantes ao atuarem concertadamente na existência cotidiana (MAGALHÃES, 2003, p. 28).

É nesse mundo da vida que emergem as demandas dos sujeitos e seus anseios por mudança no atendimento às suas necessidades e nas decisões do Estado. Nesta experiência dialógica, construída pela interação comunicativa livre de coerções, os sujeitos passam a apresentar numa esfera pública mais ampla seus anseios e desígnios, e lutam para modificar seu contexto social e político. A sociedade civil é responsável por esse processo, pois são associações e organizações livres do Estado e do Mercado, ou seja, não estatais e não econômicas, as quais ancoram as estruturas de comunicação das esferas públicas nos componentes sociais do mundo da vida. O Mundo sistêmico é o outro polo em relação ao mundo da vida. Ele pode ser entendido como os contextos empíricos onde a ação racional incide em suas diferentes formas. Ele também coloca a ação 
comunicativa em contextos sociais (MAGALHÃES, 2003). No mundo da vida se ancora a gestão social, e o mundo sistêmico ampara o modelo de administração pública gerencial. O mundo sistêmico é compreendido pela economia e pelo aparato estatal, no qual a instância econômica passa a ser o grande elemento configurador da visão de mundo das pessoas e não mais a política. Nesta lógica do sistema, a argumentação é secundária. O sistema "deve ser pensado como o conjunto normativo mais ou menos explícito de regras e procedimentos que ordenam a sociedade, racionalizando, no sentido técnico, as formas de ação" (MAGALHÃES, 2003, p. 29). Esse mundo sistêmico é pautado pela própria lógica instrumental, pelas relações impessoais, um mundo de subjetividades, que busca resultados que atendam ao bom desempenho administrativo e técnico do Estado e ao lucro e a produtividade do mercado (HABERMAS, 1989).

Frente a estes dois "mundos", a gestão social, como prática discursiva e projeto político, ao requerer a existência de fluxos comunicativos oriundos da esfera pública, pode promover a interação entre as demandas próprias do mundo da vida e o mundo sistêmico (ou um Estado que se move pela razão instrumental). Desta forma, a prática da gestão social tem o potencial de tornar visíveis as demandas do mundo da vida, influenciando a realidade política do Estado. Para a concretização desse projeto de gestão social, o Estado deve ser permeável a um processo inclusivo à formação de interesses gerais. Além disso, a gestão social, como cunhado até aqui, pode evitar a colonização do mundo da vida pelo mundo sistêmico, ou seja, que a vida íntima, privada e associativa seja permeada pela lógica do mercado e do Estado. A colonização do mundo vivido pelo sistema implica restrição das suas possibilidades comunicativas próprias.

Para Guerreiro Ramos (1989), expoente dos estudos críticos no campo dos estudos organizacionais, a Racionalidade, como em Habermas, é um ponto chave do entendimento do comportamento humano. Guerreiro Ramos lança mão da noção de Racionalidade Utilitária e Racionalidade Instrumental para erigir a ideia de que a ação humana na modernidade é guiada pelo utilitarismo e pela instrumentalização das relações sociais. Esse processo afeta sobremaneira as decisões coletivas e os sistemas de gestão, no caso dos estudos da racionalidade em organizações. A racionalidade instrumental em Guerreiro Ramos é baseada nos fins, no utilitarismo carregado para as decisões sobre as ações. Esta racionalidade se contrasta com o que autor chama de racionalidade substantiva, que se assemelha à racionalidade comunicativa de Habermas. A racionalidade substantiva baseia-se no uso da razão fundada na ética e na moral, e a racionalidade instrumental baseia-se no utilitarismo.

De forma complementar, a teoria da ação comunicativa de Habermas, como apontado por Serva (1997), a racionalidade instrumental ou utilitária em Guerreiro Ramos, assim como em Habermas, diferem-se da substantiva (ou comunicativa, no caso de Habermas) pelo peso que conferem à economia na determinação da vida social. Por outro lado, a racionalidade substantiva dá maior ênfase ao social e ao político. Para Serva (1997), as críticas feitas por Guerreiro Ramos são fundamentais para analisar as bases instrumentais e utilitárias da Administração e da Gestão Pública, o que implica a discussão da dicotomia entre administração e política.

No caso da administração pública, o enfoque na Administração eficiente, utilitária, determina os padrões de desempenho e aquilo que deve ser considerado "sucesso". Inclusive, normalmente, as mensurações de resultados de cunho quantitativo não revelam como resultados os ganhos políticos subjacentes aos processos desencadeados. O que orienta os padrões estabelecidos ao desempenho dos administradores públicos são regras e leis baseadas nas concorrências de mercado.

Facilmente veremos departamentos e setores da administração pública em busca de metas a serem atingidas, de quantificações de reuniões assistidas, de visitas realizadas, de convênios firmados. São padrões informativos, quantitativos, que referenciam uma lógica de eficiência que se assenta mais na administração e na burocracia, do que propriamente na realização qualitativa dos processos políticos. A lógica instrumental e utilitária, por sua vez, abre caminhos às patologias do serviço público, como os desvios de conduta e a corrupção, pois afasta os processos éticos e morais da pauta governamental. Nesta tese, pensar a gestão social como prática discursiva e projeto político é desvelar estas racionalidades e interpretar o adjetivo "social" como meio de os próprios indivíduos se tornarem sujeitos sociais, expressando pretensões de validade, demandas e diferenças, extrapolando o foco na subjetividade em direção ao plano das intersubjetividades fundadas em processos argumentativos. A gestão social seria, assim, uma prática dialógica capaz de produzir uma crítica comunicativa da sociedade, politizando-a, emancipando-a, pelo exercício da busca do consenso, das amarras de uma racionalidade utilitária e instrumental.

Para que a emancipação aconteça e a colonização possa ser evitada, a gestão social precisa se fortalecer como projeto político e se deflagrar como prática discursiva. É nas deliberações engendradas nas esferas públicas, livres e autônomas, que os sujeitos, independentemente das instituições, podem instaurar processos públicos de discussão. Uma visão procedimental é 
importante na medida em que oferece parâmetros para se verificar o processo deliberativo não apenas formalizado em instituições, mas no espaço mesmo da vida social (HABERMAS, 1997).

Porém, é preciso ter claro que as discussões não governam, elas são responsáveis por gerar o poder comunicativo, que não substituem o poder administrativo, mas devem influenciá-lo. Sob a afirmativa de que quem governa é o poder administrativo, Habermas (1989) enfatiza a importância do poder comunicativo dos sujeitos autônomos na formação de opiniões majoritárias frente ao poder administrativo, sendo esse o único capaz de traduzir em ações efetivas as demandas sociais.

Voltamos aqui à dicotomia entre Administração e Política. O poder administrativo é orientado pela razão técnica e instrumental e, ao instrumentalizar o uso de termos como "participação" e "gestão social", despolitiza-o. Mas, como afirma Habermas (1997), todo sistema dominante é passível de fissuras. E essas fissuras só acontecem no momento em que os sujeitos reconhecem que o sistema não acopla os interesses coletivos e públicos. É a construção de um projeto político que, junto a uma ação comunicativa, influencia deliberadamente o poder administrativo.

Nesta concepção, o antagonismo entre Estado e Sociedade civil, que comumente se vê em algumas abordagens teóricas, cede lugar às possibilidades de uma ação conjunta para o aprofundamento da democracia. Essa relação é sedimentada na ampliação das oportunidades de participação da sociedade, que está atrelada ao próprio esforço de criação das esferas públicas, onde o exercício de poder do Estado pudesse ser compartilhado.

Este exercício da participação política, em Habermas, é considerado como um "processo de aprendizagem". O estabelecimento de um fluxo comunicativo por meio deste processo é elemento crucial para ampliar as chances de garantir a liberdade e alcançar o bem comum (HABERMAS, 1997). Avritzer e Costa (2004), inspirados na teoria de Habermas, acreditam que a prática da participação e o envolvimento nos assuntos públicos teriam um efeito conscientizador sobre a responsabilidade da liberdade dos cidadãos. A constituição de uma esfera pública, conscientizada de suas responsabilidades, conteria e influiria as ações do Estado e do Mercado. Abrir-se-ia, assim, um "espaço para uma nova forma de relação entre racionalidade e participação" (AVRITZER e COSTA, 2004, p. 705).

Nesta perspectiva, a sociedade civil consegue se articular com o Estado e institucionalizar suas demandas. Os espaços públicos de participação da sociedade passam então a compor as esferas públicas. Cabe aos atores da sociedade civil, neste modelo de democracia deliberativa, um papel duplo:

“[...] de um lado eles são responsáveis pela preservação e ampliação da infra estrutura da comunicativa própria do mundo da vida e pela produção de microesferas públicas associadas à vida cotidiana. Ao mesmo tempo, tais atores canalizam os problemas tematizados na vida cotidiana para a esfera pública" (AVRITZER e COSTA, 2004, p. 709).

A identificação, compreensão e canalização das demandas e problemas da sociedade pressupõem que estas sejam assumidas como políticas públicas e sejam executadas pelos instrumentos administrativos do Estado. Com a constituição de espaços públicos, ocorreria a interação dialógica entre a sociedade civil e o Estado, possibilitando decisões sobre estas políticas ${ }^{6}$. Esse processo caracterizaria a introdução do elemento "social" na esfera decisória do Estado: a prática da gestão social é o resultante desta operação.

\footnotetext{
${ }^{6}$ A literatura sobre o tema (por exemplo Avritzer, 2000) aponta para uma ampliação do espaço público como a possibilidade de discussão e deliberação sobre políticas públicas e a democratização do processo decisório, possibilitando também a gestão social.
} 


\section{CONCLUSÕES}

À guisa de uma conclusão, pode-se apontar que, assim como o mundo sistêmico e o mundo da vida, a administração pública gerencial e a gestão social não são mutuamente excludentes, mas podem se conciliar. Não veremos uma gestão pública que não tenha traços gerencialistas, e não haverá o fim de espaços de participação social e de processos políticos participativos num regime político democrático. A política dialógica e a política instrumental podem entrelaçar-se no campo das deliberações.

As argumentações lançadas neste ensaio tentaram evidenciar a presença de diferentes projetos políticos no interior do Estado. Por um lado, um projeto neoliberal de razão instrumental, com concepções minimalistas a respeito da política e da democracia. Por outro, um projeto político cunhado na gestão social, que, centrando-se na política mais que na administração, não se define estritamente por instrumentos administrativos para conceber a argumentação como processo de formação das vontades gerais e de condução do governo.

Assim, ao definir gestão social como projeto político e prática discursiva, queremos desvelar seu caráter emancipador e transformador da realidade social e política. A prática da gestão social, que se concebe no uso da razão comunicativa, pode transformar o poder comunicativo, que emerge das esferas públicas livres, em poder administrativo, o que vai permitir a influência sobre as decisões e ações políticas do Estado. Esse potencial transformador, garantido pelo engendramento de fluxos comunicativos que se manifestam das interações sociais, é fundamental para evitar a colonização do mundo da vida pelas lógicas instrumentais do Mercado e do Estado.

A gestão social, como apresentada neste texto, remete a um processo em que os próprios indivíduos se tornam sujeitos sociais, expressando, nos atos de linguagem, suas demandas e anseios, e aproximando o Estado do verdadeiro sentido do "social" que caminha junto com a gestão pública. Para isso, a Administração pública necessita mover-se do foco na subjetividade técnica para o plano das intersubjetividades fundadas na linguagem.

Talvez a mais importante contribuição dos postulados Habermasianos para esse sentido de gestão social tenha sido revelar um aspecto procedimental (argumentativo) necessário à superação das amarras técnico-instrumentais de uma gestão pública gerencial. Porém, Habermas não leva em consideração a existência do conflito, inerente aos espaços públicos e ao confronto de ideias. Reside aí, pelo embasamento teórico e o caráter ainda preliminar desta discussão, uma lacuna no desenvolvimento deste ensaio. Temos claro, porém, que esta é uma das vias para a expansão crítica destes argumentos, ressaltando os conflitos e as assimetrias de poder que perpassam os espaços públicos e distinguem a atuação dos diferentes atores. Mas este ensaio não teve a pretensão de esgotar a discussão e, independente dos hiatos teóricos em pauta, ele é apenas mais um ponto de partida na longa caminhada acadêmica à consolidação da noção de Gestão Social.

Ciente de que o mundo da vida real é diferente do ideal discursivo de Habermas, uma última sugestão ao avanço do campo científico da gestão social seria buscar o aprofundamento sobre a teoria discursiva da moral ou a ética do discurso. Ela se caracteriza como uma posição filosófica que lança mão de um procedimento argumentativo, o discurso, a fim de solucionar problemas e conflitos de ordem moral na sociedade atual e complexa. Para a gestão social, o estabelecimento de uma ética discursiva seria uma guinada na direção de mais um passo para sua robustez teórica. 


\section{REFERÊNCIAS}

AVRITZER, L.; COSTA, S. Teoria crítica, democracia e esfera pública concepções e usos na América Latina. Revista de Ciências Sociais, Rio de Janeiro, v. 47, n. 4, p. 703-728, 2004.

BRESSER PEREIRA, L. C. Crise econômica e reforma do estado no Brasil: para uma nova interpretação da América Latina. São Paulo: Atlas, 1996.

CANÇADO, A. C.; TENÓRIO, F. G.; PEREIRA, J. R. Gestão social: reflexões teóricas e conceituais. Cad. EBAPE.BR, v. 9, n. 3, p. 681-703, Set. 2011.

CANÇADO, A. C.; PEREIRA, J. R.; TENÓRIO, F. G. Gestão social: epistemologia de um paradigma. Curitiba: CRV, 2013.

CANÇADO, A. C.; PEREIRA, J. R.; Tenório, F. G. Gestão social: epistemologia de um paradigma. 1. ed. Curitiba: CRV, 2013. v. 1. 216 p.

CARRION, R.; CALOU, A. Pensar a gestão social em Terras de "padinho Cícero". In: SILVA JUNIOR, J. T. et al. (Org.). Gestão Social: Práticas em Debates, Teorias em Construção. 1. ed. Fortaleza: Impressa Universitária/UFC, 2008.

DAGNINO, E. Construção democrática, neoliberalismo e participação: dilemas da confluência perversa. Política \& Sociedade, v. 3, n. 5, p. 139-164, 2004.

EVANS, P. Além da "Monocultura Institucional": instituições, capacidades, e o desenvolvimento deliberativo. Sociologias, Porto Alegre, v. 5, n. 9, p. 20-63, jan./jun. 2003.

FADUL, É.; SOUZA, R. de. "Analisando a interface entre o gerencialismo, a criação das agências reguladoras e a inovação institucional". In: Encontro da Associação Nacional de pós-graduação em administração, 30, 2006, Salvador. Anais... Salvador: ANPAD, 2006.

FRANÇA FILHO, G. C. Gestão Social: Um Conceito em Construção. In: IX Colóquio Internacional Sobre Poder Local - II Colóquio Internacional El Análisis De Las Organizaciones Y La Gestión Estratégica: Perspectivas Latinas. Anais... Salvador-Bahia, 2003.

FRANÇA FILHO, G. C. Definindo Gestão social. In: SILVA JUNIOR, Jeová Torres; MASIH, R. T.; CANCADO, A. C.; SCHOMMER, P. C. (Org.). Gestão Social: Práticas em Debates, Teorias em Construção. 1. ed. Fortaleza: Impressa Universitária/UFC, v. 1. 2008.

FREITAG, B. Sistema e "mundo vivido". Revista do GEEMPA, v. 5, n. 3, p. 61-73, jul. 1993.

GIDDENS, A. O Estado-nação e a Violência. Segundo Volume de uma Crítica Contemporânea ao Materialismo Histórico. São Paulo: Edusp, 2001.

GUERREIRO RAMOS, A. A nova ciência das organizações: uma reconceituação da riqueza das nações. Rio de Janeiro: FGV, 1989.

HABERMAS, J. Consciência moral e agir comunicativo. Rio de Janeiro: Tempo Brasileiro 1989.
HABERMAS, J. Direito e democracia: entre facticidade e validade. 2. ed. Tradução de Flávio Beno Siebeneichler. Rio de Janeiro: Tempo Brasileiro, 1997.

JUNQUEIRA, L. A. P. et al. Parcerias e Redes Sociais: a busca pela gestão social eficaz - um estudo de caso. In: III Encontro Nacional de Pesquisadores em Gestão Social. 3, Juazeiro, 2009. Anais... Juazeiro, ENAPGS, 2009

MAGALHÃES, R. F. Racionalidade e Retórica: teoria discursiva da ação coletiva. Juiz de Fora: Clio Edições Eletrônicas, 2003. 138 p.

MARQUES, Â. C. S. A ética do discurso e a formação do sujeito político em Habermas. Cadernos da Escola do Legislativo, v. 15, n. 23, p. 161-183, 2013.

OFFE, C. Capitalismo Desorganizado: as transformações contemporâneas do trabalho e da política. 2. ed. São Paulo: Brasiliense, 1995.

PAES DE PAULA, A. P. Administração pública brasileira entre o gerencialismo e a gestão social. RAE - Revista de Administração de Empresas, v. 45, n. 1, p. 36-49, jan./mar. 2005.

SANTOS, B. de S.; AVRITZER, L. Para ampliar o cânone democrático. In. SANTOS, B. de S. (Org.). Democratizar a democracia: os caminhos da democracia participativa. Rio de Janeiro: Civilização Brasileira, 2002. 39-83 p.

SANTOS, B. de S. A crítica da razão indolente: contra o desperdício da experiência. 4. ed. São Paulo: Cortez, 2002.

SARAVIA, E. J. Administração Pública e Administração de Empresas: Quem Inspira a Quem? Revista ADM.MADE, v. 14, n. 3, p. 1-8, outubro/dezembro 2010.SERVA, M. A racionalidade substantiva demonstrada na prática. Revista de Administração de Empresas: São Paulo, v. 37, n. 2, p. 18-30, abr./jun. 1997.

SERVA, M. A racionalidade substantiva demonstrada na prática. Revista de Administração de Empresas: São Paulo, v. 37, n. 2, p. 18-30, abr./jun. 1997.

SOUSA, J. L.; PAIVA JR., F. G. Os novos tempos e a administração pública: as amarras da racionalidade instrumental e da regulação social. Revista Gestão Pública: Práticas e Desafios, Recife, v. I, n. 1, p 99-118, fev. 2010.

TENÓRIO, F. G. "Gestão social: uma perspectiva conceitual". Rev. Adm. Pública, Rio de Janeiro, v. 32, n. 5, p. 7-23, set./out. 1998.

TENÓRIO, F. G. (Re)visitando o conceito de Gestão social. In: SILVA JUNIOR, J. T. et al (Org.). Gestão Social: Práticas em Debates, Teorias em Construção. 1. ed. Fortaleza: Impressa Universitária/UFC, 2008.

WEBER, M. Metodologia das ciências sociais. Tradução de Augustin Wernet. 4. ed. Editora Cortez: São Paulo, 2001. 


\section{Alan Ferreira de Freitas}

Doutorando em Extensão Rural pela Universidade Federal de Viçosa (UFV); Professor do Departamento de Administração e Contabilidade da UFV. E-mail: alanf.freitas@ufv.br

\section{Alair Ferreira de Freitas}

Doutor em Administração pela Universidade Federal de Minas Gerais; Professor do Departamento de Economia Rural da UFV. E-mail: alair.freitas@ufv.br

\section{Marco Aurélio Marques Ferreira}

Pós-Doutorado em Administração Pública pela Rutgers University (EUA); Professor do Departamento de Administração e Contabilidade da UFV; Coordenador do programa de Pós-graduação em Administração da UFV. E-mail: marcoaurelio@ufv.br 